\title{
Diplomáticos y cónsules españoles de América, 1892-1936
}

\author{
Isidro Sepúlveda Muñoz *
}

Las relaciones oficiales entre España y las repúblicas americanas durante todo el siglo xix alcanzaron el dudoso equilibrio entre escasas y tensas. El reconocimiento por España de los nuevos estados surgidos de las guerras de emancipación se llevó a cabo siguiendo los dictados de aquellos que mantenian que sería más beneficioso para la ex-metrópoli una negociación bilateral con cada gobierno. Esto tuvo como consecuencia el rosario de tratados de reconocimiento que se extendió desde 1836 hasta 1896. Una vez establecidas las relaciones diplomáticas, otros motivos favorecieron el mantenimiento de escasos y poco fluidos contactos: persistencia española de cierto deseo de reconquista (hasta la década de los sesenta), nacionalismo anti-hispanista en la mayoria de los nuevos estados, pocos intercambios comerciales y la permanencia de España todavía como metrópoli de sus dos últimas colonias americanas, Cuba y Puerto Rico, pueden ser señalados como los más importantes.

Durante las últimas décadas del siglo xix y primeras del $x x$ estos motivos variaron sustancialmente; la pérdida de Cuba y Puerto Rico, al tiempo que hacia desaparecer una causa tenida como agravante por gran parte de la intelectualidad americana, potenció la explicitación de la amenaza estadounidense sobre el resto del continente americano. Esto hizo que el anti-hispanismo disminuyera, al tiempo que surgian corrientes de opinión claramente favorables a un acercamiento profundo con España. Lo que propició el crecimiento de contactos intelectuales, siendo común el paso de autores literarios y académicos, lo que hizo que por primera vez $\rightarrow$ si bien en pequeña escala - pueda hablarse de un mercado editorial hispano-americano. Por su parte, el retorno de los capitales cubanos y la pérdida del comercio ventajoso con las Antillas conllevó la necesidad de

\footnotetext{
* Departamento de Historia Contemporánea.
} 
ampliar los intercambios comerciales y diversificar ofertas y destinatarios; con todo, unas politicas proteccionistas impedian el fomento de estos intercambios. La causa más importante, con serlo todo lo anterior, fue sin embargo la entrada en las distinias repúblicas americanas de un gran contingente de emigrantes, evaluado para el conjunto de la época en cerca de dos millones y medio de españoles.

El presente trabajo pretende examinar el papel que los representantes oficiales españoles tuvieron en este aumento de las relaciones. Con ser importante su número y ubicación, más trascendencia tiene el cumplimiento de su labor, la percepción de las sociedades americanas, sus relaciones con la colonia y el uso diario con el que estos representantes debian desempeñar su tarea.

\section{CANTIDAD Y UBICACIÓN DE LA REPRESENTACIÓN DIPLOMÁTICO- CONSULAR}

La representación diplomática y consular española en las repúblicas americanas fue muy reducida, especialmente si se la compara con la red de legaciones y consulados en Europa.

La representación diplomática y consular española en América en el año 1892, contra en lo que en ocasiones se ha afirmado por quienes han estudiado la coyuntura del centenario, no sufrió ningún reforzamiento para dar mayor proyección a las conmemoraciones del IV Centenario del descubrimiento. Desde finales de los años setenta se mantenían nueve legaciones, en Argentina, Brasil, Colombia, Chile, Guatemala, México, Perú, Uruguay y Venezuela; donde estaban acreditados nueve Ministros Plenipotenciarios de diferentes categorias y diez secretarios. La representación se complementaba con once delegaciones consulares, en Buenos Aires y Rosario, Río de Janeiro, Valparaiso, Guayaquil, Veracruz y México, El Callao, Santo Domingo, Montevideo y La Guaira (para 1892 se habia suprimido el consulado en Rio); estaban atendidas por otros tantos cónsules de primera y segunda categoria. Por tanto, seis paises se encontraban sin ningún tipo de representación española en tan señalada fecha, y asi lo seguirian estando durante buena parte del periodo estudiado (Bolivia, Costa Rica, El Salvador, Honduras, Nicaragua y Paraguay). El resto de la década del noventa permaneció prácticamente inalterable la plantilla de representación española.

En 1900 España mantenia representación diplomática en nueve Estados americanos; tres Enviados extraordinarios y Ministros Plenipotencia- 
rios (en Chile, México y Perú), seis ministros y nueve secretarios de diferentes categorías administrativas eran los agentes diplomáticos acreditados ' ${ }^{1}$. Cinco años después aún se mantenia este descenso, aunque se habian aumentado en una las representaciones diplomáticas (Cuba, 1903); el cambio más significativo habia sido la elevación de su categorías por el sencillo método de nombrar a los Ministros Plenipotenciarios (la mayoria de ellos también Cónsules generales) como Enviados extraordinarios; de éstos en 1905 habia nueve, contra un sólo ministro; completaban el cuerpo en América diez secretarios de primera y segunda clase. Esta tendencia se mantuvo hasta la guerra mundial; en 1910 los diez ministros tenian categoria de enviados extraordinarios; eran ayudados por once secretarios, siendo la representación en Argentina la que presentaba dos secretarios por primera vez. La mayor innovación fue el nombramiento de agregados militares en las más importantes representaciones: Argentina, Chile y México. El total de los agentes sólo ascendia a $25^{2}$. Unos años después se creó la legación española en El Salvador, a cargo de un secretario de primera, con lo que las representaciones diplomáticas españolas en América eran once. En este número se mantuvo la representación hasta fecha tan tardia como 1928.

En 1915 el Estado español mantenia ocho embajadas; todas, excepto una, Washington, estaban en Europa: Berlin, Londres, Paris, Roma, San Petesburgo, Santa Sede y Viena; ninguna de ellas en un pais de ámbito hispano. De los 25 ministros repartidos por todo el mundo, 11 se encontraban en estos paises (en El Salvador lo era interinamente el Encargado de negocios). No habia ningún consulado general de los 11 establecidos; como en las embajadas, Europa monopolizaba la casi totalidad (con la única excepción de Nueva York). De los 86 cónsules de carrera, 30 se encontraban en América ${ }^{3}$.

La guerra mundial posibilitó una mayor aceptación de los sectores que reclamaban un más notorio acercamiento hacia América ${ }^{4}$. Esta politica obtuvo como principal plasmación, casi única, la elevación en 1917 de la representación española en Buenos Aires a la categoría de Embajada. El preámbulo del decreto que la establecia era explicito de las causas que lo motivaron:

Boletin Oficial del Ministerio de Estado (BOME), 30-XII-1898, págs. 473-479,

BOME, diciembre de 1905 y 1910.

BOME, 20-XII-1915, págs. 120-144.

“ Altamira, R.. España y el programa americanista. Madrid, Ed. América, 1917. Vehils, R., Delegación parlamentaria para las relaciones con América y Unión Interparlamentaria Hispanoamericana. Barcelona, Casa de América-Mercurio, s.a. [1915]. 
“El grado de prosperidad alcanzado por la República Argentina; los vinculos de raza que a ella nos unen y que tienen su principal apoyo en el crecido número de españoles que hallan en aquel país ancho y hospitalario campo a su actividad y sus iniciativas, creando intereses materiales que cada dia aumentan y se consolidan» 5.

Este "gesto" tuvo una importancia considerable en el crecimiento de las relaciones de España con América. Su mayor trascendencia quedó puesta de manifiesto en los comentarios de sectores hispanistas de algunos países americanos (Chile, México, Cuba) por reclamar el mismo trato dispensado a Argentina. La más directa reacción a la primera embajada española a América la dio el gobierno mexicano, reclamando la necesidad de establecer una legación de semejante rango ${ }^{6}$.

La reactivación de las relaciones tras la guerra mundial, que tuvo una repercusión directa en el incremento de la categoría en la representación diplomática, tardó tres años en hacerse notar en la consular. En 1920 el número de consulados españoles en América pasó de 24 a 34, creándose los de Mendoza y Bahía Blanca (Argentina), Bahía y Pernanbuco (Brasil), San Salvador (El Salvador), Guatemala, Tegucigalpa (Honduras) y Managua (Nicaragua); el número de cónsules en consecuencia se amplió considerablemente, pasando de 29 a 40 (misma cantidad que en los finales años de la República). En 1923 se creó un segundo consulado en Chile, en la capital Santiago.

La estructura de la representación oficial española en América presentó durante gran parte de los años veinte una deficiente presencia. Existia una sola embajada (Buenos Aires) y 10 legaciones; ocho paises no tenían ninguna representación diplomática estable: Honduras, Nicaragua, Costa Rica, Panamá (dependientes de la representación en Guatemala), Ecuador, Bolivia (en Perú), Paraguay (en Argentina) y la República Dominicana (en Cuba). Esta deficiencia se acusaba aún más si se tiene en cuenta el carácter decimonónico que se mantenia en la distribución de las representaciones españolas en el extranjero, marcadamente eurocentrista. De las ocho embajadas existentes en 1923 seis estaban en Europa; Roma reunia dos, ante la Santa Sede y ante el Reino de Italia. Mismo número del existente en toda América: Washington y Buenos Aires. De las 28 legaciones, 16 se mantenian ante gobiernos europeos, 10 ante americanos y dos ante asiáticos ${ }^{7}$. Todo esto denota el mantenimiento de

Real Decreto 8-VIII-1916; Gaceta, 9-VIII-1916.

${ }^{6}$ Memorándum para S. M. el rey D. Alfonso XIII; Madrid, 15-XI-1919; Archivo Histórico Diplomático “Genaro Estrada». México D.F. (AGE), Exp. 17-11-182.

BOME, 30-XII-1922, págs. 667-674. 
la concepción de la diplomacia como relaciones entre Estados a nivel estrictamente politico, sin tener apenas en consideración las necesidades económicas, culturales y sociales. Si la distribución ya marcaba un continuismo con respecto a los usos del siglo xIX, éstos se ponen en evidencia con la permanencia del ejercicio de la caduca «diplomacia de salón»; máxime cuando diplomáticos educados para ejercer óptimamente su cometido en Paris o Berlín, eran destinados a La Paz o México ${ }^{8}$.

A este panorama reaccionó la dictadura primorriverista en su etapa civil, desarrollando una nueva concepción de la carrera diplomática y, lo que más importa aqui, aumentando notablemente tanto el número como el rango de las representaciones españolas. En este periodo no hubo ningún pais americano que no recibiera algún tipo de representación, estando en la mayoria presentes legaciones diplomáticas y delegaciones consulares (sólo Costa Rica, Honduras, Nicaragua, Panamá, Paraguay, República Dominicana y Puerto Rico - por obvias razones- tenian representación únicamente consular). Los años de 1927 a 1930 fueron el periodo en que mayor cantidad y cualificación llegó a tener la representación de España en América, significando la etapa republicana en este sentido un retroceso; no fue hasta veinte años después cuando se igualó el número y la cantidad de legaciones y diplomáticos españoles en América. 1926 fue sobre todo el año de la elevación del rango de la legación en La Habana a la categoría de embajada ${ }^{9}$. Dos años después, se elevaba la categoria de la legación en Chile, pero mediante el procedimiento de otorgar al Ministro plenipotenciario en Santiago cartas de embajador ${ }^{10}$. En 1929 se formalizaba la representación diplomática con Bolivia y Ecuador y en los presupuestos para el año 1931 ya se incluian las instalaciones de las delegaciones en Paraguay y la República Dominicana. El número de diplomáticos de carrera pasó de 25 en 1924 a 35 en 1929 y 41 en los presupuestos para 1931.

La representación consular sufrió también un aumento considerable. En 1927 se establecieron consulados en La Plata (Argentina), Portoalegre (Brasil) y Camagüey (Cuba); dos años después se creaban los consulados en Tucumán (Argentina), Barranquilla (Colombia), Valdivia y Antofagasta (Chile, suprimidos al año siguiente) y Torreón (México). 1929 fue por tanto el año de mayor número de consulados españoles en América, 44. El número de cónsules de diferente clase pasó de 41 en 1924 a 52 en 1929.

\footnotetext{
${ }^{8}$ El manual tenido como ejemplar era Castro y Casaleiz, A. de, Guia práctica del Diplomático español. Madrid, Est. Tip. “El Correo», 1886; 2 vols.; especialmente el capitulo "La misión del diplomático", págs. 43 ss.

${ }^{9}$ BOME; 30-VI-1926.

${ }^{10}$ Real Decreto 1-VI-1928; Gaceta, 3-VI-1928.
} 
Crisis económica, potenciación de la calidad en lugar de la cantidad y desconfianza en el cuerpo diplomático heredado de la monarquía fueron en distinta medida las causas de que el periodo republicano se caracterizara en el campo de la representación española en América por una ligera disminución del número de legaciones (El Salvador, 1935) y consulados (Puebla y Torreón, 1933; Bogotá y Camagüey, 1934) y, paralelamente, del personal de éstas y otras legaciones y consulados. El número de ministros pasó de 14 a 10 , el de secretarios de 24 a 21 y el cónsules de 43 a 40 . Lo más importante fue la elevación de las legaciones de México y Brasil, que por el número de españoles residentes en estos paises, los intercambios comerciales y los intereses de todo tipo requerian la medida tanto o en mayor número que en Cuba o Chile.

\section{LA FORMACIÓN Y DEDICACIÓN DE LA REPRESENTACIÓN DIPLOMÁTICO-CONSULAR EN AMÉRICA}

Si el número de representaciones y de agentes diplomáticos era reducido, la selección y preparación de éstos no era en absoluto una garantía para solventar tal deficiencia. Una de las críticas más acerbas sobre la categoria moral y profesional de los diplomáticos españoles se produjo desde sus propias filas, tan dadas a la preservación y defensa del corporativismo, de la mano de Francisco Agramonte; primer subsecretario del Ministerio de Estado en el periodo republicano ${ }^{11}$.

Dividió a sus compañeros en tres categorias; la primera estaba constituida por los "frescos, viciosos, locos, necios, etc.", que deshonraban el cuerpo y atentaban contra la imagen y el prestigio de España en el extranjero; a éstos "habría que echarles fuera de una plumada» ${ }^{12}$. La segunda categoria la formaba «un grupo bastante numerosos de sujetos desaprensivos y cucos", quienes trabajaban con ahinco sólo cuando habia posibilidad de un ascenso o premio; para conseguir la desaparición de su "hacer que hacemos" era necesario "obligarlos desde arriba a andar

\footnotetext{
"Francisco Agramonte y Cortijo; Expediente personal; Archivo del Ministerio de Asuntos Exteriores (AMAE), pág. 349, n. ${ }^{\circ} 24.437$.

12 “Un histérico que nos pone en ridiculo a los ojos extranjeros, un borracho inveterado o un cretino no hay razón para conservarlos en la Carrera. Ni deben estar en el extranjero donde atentan al decoro de España ni en el Ministerio donde hace falta un personal capaz de dirigir a los que están fuera." AGRAMONTE, F., "Bases para la reforma del cuerpo diplomático español». Berlin, marzo de 1927; Archivo Historico Nacional (AHN), Presidencia de Gobierno, leg. 323.
} 
derechos", lo que redundaria en el "rendimiento sensible en pro de los intereses nacionales que, hoy por hoy, no aparecen por ninguna parte". El tercer grupo, "por desgracia bien reducido", lo integraban quienes trabajaban bien y de modo continuo; para éstos, el apoyo de sus jefes y la supresión de las trabas burocráticas, elevadas por quienes no tenian otro modo de disfrazar su inoperancia, eran la mejor recompensa ${ }^{13}$.

Las obligaciones del personal diplomático y consular en paises extranjeros era doble: la representación del Estado español en cada uno de esos paises y el envio al Ministerio de Estado de toda la información. Los repetidos requerimientos para que la segunda parte se efectuara de modo regular atestiguaba el deficiente cumplimiento de los deberes informativos ${ }^{14}$. Pero además, los representantes españoles en los países americanos tenian una tercera y muy trascendental obligación: atender la numerosa colonia de emigrantes.

Si no tanto por las dos primeras funciones, para la tercera la representación oficial española adolecia de notorias carencias. En un informe sobre el estado de la red consular, un ministro español señalaba las tres principales deficiencias de los cónsules españoles: eran pocos (y mal respaldados por la ausencia de personal administrativo), sus retribuciones eran «irrisorias" y su preparación para el puesto "deplorable" ${ }^{15}$. Aunque su espiritu corporativo se lo impedia, el informe del ministro podia haber sido extrapolable a toda la representación diplomática. Desde el punto de vista del español residente la opinión no era mas positiva:

"Nuestros distintos gobiernos han mirado y continúan mirando su representación en América con poco interés; y envían ministros mal retribuidos y peor dispuestos; dándose el caso risible [...] de tener por ministro a una persona que apenas si mal pronuncia el castellano" ${ }^{16}$.

La causa de la ausencia de ayuda hacia la emigración tenia un origen doble: la ausencia de medios económicos y el concepto de utilidad pública que los diplomáticos españoles tenian de su representación. Estos eran, en primer y casi único lugar, funcionarios para la representación politica de España con cualquier pais donde existiera una legación. En cuanto a los cónsules, su misión básica era proveer de informes al Mi-

${ }^{13}$ Ibidem, págs. 4-5

${ }^{14}$ Real Orden, 28-VIII-1919; Circular n. ${ }^{\circ} 638$ del Ministerio de Estado

${ }^{15}$ Marqués de Desio al Ministerio de Estado (M. E.); México, 8-I-1926; AMAE, leg. H-2565.

${ }^{16}$ Fernandez Pesquero, J., España en Chile. Monografia de la colonia española en Chile. Cádiz, Manuel Álvarez Imp., 1914; pág. 6. 
nisterio, servir de notarios para la colonia y recaudar los impuestos que por diversos conceptos debia recibir la hacienda española ${ }^{17}$. La ayuda a los compatriotras emigrados no entraba dentro de sus atribuciones y, por tanto, no puede decirse que fuera una práctica demasiado ejercida; como un periódico de la colonia se quejaba, estaban más preocupados en mantener un «patriotismo belicoso, [lanzados] personalmente a la poco diplomática misión de que ondeara la bandera de España en un lugar un metro más alto que la de cualquier otro país» ${ }^{18}$. Las quejas encontraron eco en el ánimo del propio Primo de Rivera. Nada más reasumir la dirección de la politica exterior, en un decreto concediendo carácter oficial a la Asociación de Españoles de Ultramar y sin que fuera en nada pertinente, se pide a todos los representantes diplomáticos y consulares «la más decorosa y diligente organización de los servicios y el más afectuoso trato a todos los españoles, por humildes que sean, habida cuenta que el prestigio exterior de la nación depende en mucho del acertado desempeño de este servicio» ${ }^{19}$. Lo que no impidió las quejas de numerosos diplomáticos ante las constantes peticiones de emigrantes, por entender que consideraban obligación de los representantes encontrarles un modo de sustento o, en su caso, ayudarles económicamente hasta que lo encontraran ${ }^{20}$.

En la práctica funcionarial se tenia la imagen del emigrante como un desertor, que privaba a la nación de los brazos necesarios para su desarrollo. Idea que se mantenia por buena parte de los legisladores desde el periodo de la Restauración. El mismo Segismundo Moret llegó a decir que «el español que abandona su Patria no tiene derecho a reclamar auxilio, protección ni amparo" ${ }^{21}$. No todos los representantes españoles mantuvieron posturas tan extremas como el ex-ministro de Estado, en-

17 Castro y Casaleiz, A., de, Op. cit., v. I, págs. 46-50.--Una de las obras más interesantes para el estudio de la representación consular durante el periodo republicano mantenia que los consulados debian ser "centros de información comercial española"; SEMINARıO, A., El cónsul de España en América. Madrid, Espasa-Calpe, 1935.

18 «Hace falta que venga un ministro»; El Dia Español. México, 6-VII-1927.- Ya en 1906 las quejas por el abandono a emigrantes tuvieron cabida en el Congreso, teniendo el ministro de Estado que llamar la atención al ministro español en México; vid. AGE, exp. 1515-64.

${ }^{19}$ Real Orden 9-III-1927; Gaceta, 12-|II-1927.

${ }^{20}$ Encargado de Negocios al Presidente del Consejo de Ministros; México, 27-VIII-1929; AMAE, leg. $\mathrm{H}-2565$.- - Las opiniones manifestadas para el caso de México eran comunes a todas las legaciones en América, como lo evidencia la nota al dorso del conde de San Esteban de Cañongo, ratificada por el subsecretario, Palacios; en ella se centra la crítica en «intelectuales desgraciados y compañias de artistas pobres", que exigen a los diplomáticos que les encuentren lugares donde ejercer sus labores.

${ }^{21}$ MORET, S., "Voto particular al Proyecto de ley de emigración"; en Instituto de Reformas Sociales: La emigración. Información Legislativa y Bibliografia de la Sección Primera Técnico Administrativa. Madrid, Imprenta de Sucesora de M. Muesa, 1905, pág. 113. 
contrándose numerosos ejemplos de diplomáticos y cónsules que ayudaban económica y afectivamente a aquellos que llegaban "en busca de fortuna y no han encontrado más que desengaños y muertas esperanzas", en descriptiva frase de un diplomático con extensa experiencia en América ${ }^{22}$. Los casos donde las ayudas a los emigrantes se dieron fueron en la petición de repatriaciones ${ }^{23}$ (generalmente negadas desde el Ministerio por falta de recursos), los avisos públicos para posibles herederos (que caia dentro de la responsabilidad de los cónsules) y el auxilio indigentes o "pobres de caridad" (comúnmente remitidos a instituciones de beneficencia de la propia colonia) ${ }^{24}$.

Las relaciones entre los representantes oficiales y la colonia bien establecida fueron más positivas, pero en numerosos casos distaron de ser inmejorables. La causas de este desencuentro fueron usualmente de poca importancia: simpatías personales, identificación u oposición con los gobernantes, rivalidades regionales de las que el diplomático no sabia mantenerse aparte, etc.; pero que causaron una mala impresión en el grueso de la colonia y contribuyeron mucho su alejamiento de los representantes españoles; un destacado miembro de la colonia española en Chile narraba la conducta general de éstos y sus consecuencias:

«Apenas llegan al pais se abanderan en torno a un circulo determinado de la Colonia y siguen sus desgraciados consejos aislándose del resto, infundiendo sospechas y atizando la hoguera de la discordia, malquistándose con no pocos y haciéndose indiferentes a la mayoria, que los mira de reojo y con prevención» ${ }^{25}$.

Más trascendentales fueron los enfrentamientos de carácter político, que en los años de la dictadura no hicieron sino crecer ${ }^{26}$. Con antelación los diplomáticos venian pasando periódicamente informes sobre actividades (usualmente de centros regionales o personalidades recién llegadas) contrarias al régimen turnista, algunas abiertamente antimonárqui-

\footnotetext{
22 Mobellán al M. E.; México, 26-VI-1908; AMAE, Leg. H- 1658. Por no prestar ninguna ayuda en socorrer a sus compatriotas, ataca a «estos españoles acaudalados, que tienen seco el corazón y son incapaces de tender una mano al infortunio". Semejantes narraciones e idénticas opiniones en José Caro al M. E.; Buenos Aires, 10-VI-1902; AMAE, Leg. H-2315.

23. Caso excepcional fucron las dramáticas peticiones del ministro español en México para la repatriación de la colonia ante las amenazas que hacia ella dirigian algunos sectores revolucionarios; Cologán al M. E.; México, 28-VI-1914; AMAE, Leg. H-1659.

${ }^{24}$ Molina Nadal, E., El emigrante en América. Madrid, s.e., 1913

${ }^{25}$ Fernandez Pesquero, J., España en Chile; pág. 7.

${ }^{26}$ B. Menéndez y Acebal a M. Llano Margolles, Presidente de la Asociación de Españoles de Ultramar; México, 17-IV-1927; AMAE Leg. R-255, exp. 96.
} 
cas, y no pocas en reivindicación de la cultura e identidad politica de alguna nacionalidad, catalana y vasca, principalmente.

Aún siendo común en casi todos los países algún acto que hiciera llamar el interés inquisitivo de los diplomáticos, el mayor número de estos enfrentamientos y los de mayor importancia se dieron en Buenos Aires y México. Son numerosos los despachos de ambas representaciones en los que se abordan atentados o actos deshonrosos a la bandera nacional ${ }^{27}$, injurias al Rey, "exaltación de espiritu separatista", publicaciones de dicho cariz (que se tratan de cerrar y en numerosas ocasiones lo consiguen) ${ }^{28}$. Funcionarios de especial celo en la persecución de aactos contrarios a España" fueron Bernardo Justo Cologán (México 19061912) ${ }^{29}$, o Pablo Soler, del que se conserva un seguimiento puntual de las andanzas de Blasco lbáñez en Argentina.

Si los resultados de estos diplomáticos cerca de su comunidad no pueden calificarse de buenos, la representación puramente política, motivo y fin según la propia concepción misional de estos representantes, tampoco acaparó grandes éxitos. Uno de los reproches más usuales que se les solia hacer a aquellos era la práctica de un elitismo gratuito, que en la mayoría de los casos se manifestaba con hábitos tan altaneros como alejados de la realidad ${ }^{30}$.

${ }^{27}$ Uno de los incidentes más repetidos fue la exhibición de banderas regionales con motivaciones politicas; esto hizo que el gobierno, por medio de la Real Orden de 17 de diciembre de 1908, hiciera obligatoria la colocación de la bandera española cuando bandera o escudo fuera exhibido en cualquier sociedad española en el extranjero, "patentizando asi la perfecta armonia y compatibilidad que existe entre los legitimos y respetables sentimientos regionales y el amor a España, que siempre y en todos los casos debe aparecer proclamado y consagrado". Circular del Ministerio de Estado n. 339 de 1909.

${ }^{28}$ Asi ocurrió con las revistas Azkatasuna y su continuadora, Euzkotara, que proclamaba su cometido "consagrado a la propaganda de doctrinas contrarias a la unidad de la Patria española"; Subsecretaria de Orden Público. Negociado 1; 2 de junio de 1909; AMAE H-1658.

${ }^{29}$ Distintos despachos en AMAE, Legs. H- 1657-1659. Este diplomático en absoluto mantenia una postura inflexible ante cualquier manifestación por el hecho de ser autonomista, siempre que en la «defensa de la peculiaridad regional» no se atacara o injuriara a España. Asistia con estudiada condescendencia a las fiestas de las colonias vasca y catalana, propiciando la interpretación, junto a la Marcha Real, de Els Segadors o Guernicako Arbola, ya que según su opinión «hace falta que se repitan lo bastante para que aún para los suspicaces resulte ineficaz o embotada toda malévola interpretación"; Cologán al M. E.; México, 22-IV-1908; AMAE, Leg. H-1658.

30 Fernandez Pesquero. J., España en Chile; págs. 4-6. 


\section{LA IMAGEN DE AMÉRICA A TRAVÉS DE LOS DIPLOMÁTICOS}

Una idea común entre los diplomáticos españoles era la probada inferioridad de numerosas repúblicas americanas; idea que era acompañada de un sentimiento de superioridad de España respecto a estos paises y en general sobre toda América. Esto tenia una doble consecuencia en la labor de los diplomáticos; una era la idea de prevalencia española sobre los gobiernos americanos, en algunas ocasiones llegando a minusvalorar la propia soberania de los Estados ${ }^{31}$. La otra era la búsqueda de acatamiento a la preminencia española mediante instituciones representativas; esto se manifestaba principalmente en parcelas tan significativas como el idioma y la historia; mediante la labor realizada por la Real Academia de la Lengua y la de la Historia ${ }^{32}$.

Consecuencia de la percepción de la imagen de inferioridad americana era la visión de la realidad politica de estos paises como un caos anárquico. Este caos era causado, según los casos y autores, por la venalidad de los politicos, la endogamia de la clase dirigente, la pobreza económica e intelectual de la sociedad o, incluso, por la heterogeneidad de sangres, costumbres y credos; tómese como ejemplo la descripción que se hace de México, donde se añadia a lo anterior la "anarquia revolucionaria»: "En Méjico no hay democracia, ni inquietudes, ni anhelos de perfeccionamiento [...]. En Méjico no hay moral social, ni casi moral privada; es un pais sin estructurar, descompuesto, sin un armazón que le sostenga y le ayude a caminar ${ }^{33}$. Sería demasiado extenso señalar la cantidad de imágenes, en ocasiones contrapuestas, que los diplomáticos españoles remitieron al ministerio; en lineas generales pueden señalarse como más interesantes:

- Tendencia de México y Argentina a presentarse desgajados y aparte del resto de América, distanciándose superiormente de los problemas e inquietudes especialmente de los paises de su entorno.

31 Comentando el tratado de reconocimiento y convalidación de titulos académicos firmado entre México y España, el ministro español reclamaba la necesidad de no firmar ningún otro semejante por México con otros paises europeos, pues "Méjico puede y debe conceder a España, su Madre Patria, lo que no acordará nunca con otros Estados"; M. plenipotenciario [Cologán] al M. E.; México, 10-1-1905; AMAE, Leg. H-1658.

${ }^{37}$ M. plenipotenciario al M. E.; México, 17-II-1902; AMAE, Leg. H-1658. Aprovechando la celebración en México de la Conferencia Hispanoamericana de Historia, el ministro recibió de los representantes de Argentina, Bolivia, Colombia, Chile, El Salvador, Guatemala, Honduras, Nicaragua, Paraguay, Perú y Uruguay seguridades de la creación de una academia en cada país, correspondiente de la española.

${ }^{33}$ Marqués de Rialp; México, 30-XI-1929; AMAE H-2565. 
- Condena del fragmentarismo centroamericano; así como de las pretensiones unionistas propugnadas por alguno de estos Estados cuando pretendian su hegemonia sobre el resto.

- Pretensiones de primera potencia de Argentina, Brasil y Chile; condena del expansionismo territorial chileno y brasileño, de la anglofrancofilia argentina.

- Confusión entre los intereses de las clases dirigentes y los del Estado, especialmente en los paises centroamericanos y los andinos.

- Condena de la heterogeneidad de razas, en ocasiones por las veleidades indigenistas de los gobiernos mexicano y peruano, otras por la entrada multinacional de emigrantes.

- Denuncia de la influencia de otras potencias extranjeras, de modo muy especial de Estados Unidos. Argumento muy generalizado, en el que se excluye, con agrado, el caso argentino.

Esta visión de América, en su parte negativa, no puede generalizarse para todos los diplomáticos españoles. Muchos de ellos apreciaron, e incluso alabaron el desarrollo obtenido por algunas naciones americanas. En estos casos, las observaciones partían del mismo punto de vista superior y dejan ver un marcado tono elitista. Se elogiaba la actitud de la clase politico-económica dirigente, poniéndola en contraste con la masa dificil de dirigir. Aunque no mayoritarios, los juicios racistas se hicieron sentir en una identificación de los representantes con la minoria blanca gobernante; un ejemplo extremo de esta simpatía lo alcanzó Robertí Dupuy al señalar que

"la raza blanca, descendiente de los españoles, cuyos apellidos más ilustres abundan aqui, es la menor en número, pero ha mantenido sobre las otras la supremacia que en todas partes consigue. [...] Ninguna nación americana ha conservado como Bolivia las tradiciones, usos y costumbres de la madre patria" ${ }^{34}$.

Sobre el sistema necesario para llevar a cabo esa guía, la mayoría de los diplomáticos españoles dejaban traslucir ideas aristocráticas, corporativistas y en ocasiones militaristas; estas últimas unidas a la necesidad de un hombre fuerte. Muestra de estas posturas eran las opiniones sobre Porfirio Diaz o la lectura que Maeztu hacia de la realidad politica

${ }^{34}$ Dupuy DE LOME, R., “Estudio general de la República Boliviana»; BOME, 31-III-1898; págs. 225-256. 
$\operatorname{argentina~}^{35}$. Aunque entre los diplomáticos hubo excepciones de oposición a recurrir a gobiernos de fuerza ${ }^{36}$. Sobre todo en el periodo republicano los informes denotaron un cambio sintomático, deseosamente democrático, que en ocasiones más parecian buscar la complacencia del ministerio que un análisis propio del representante.

Las posiciones más extremas contrastaban con la situación económica que podian mantener la generalidad de los diplomáticos. Los sueldos, dietas y ayuda para gastos no cubrian en la mayoria de los casos las necesidades de éstos. Las peticiones para el aumento de sueldo y gastos de representación fueron muy numerosas, dado que la carestia en algunos de los paises americanos (especialmente Argentina) obligaba a algún representante a poner de su hacienda el doble de lo que recibia de la del Estado ${ }^{37}$. En consecuencia, cuando estas posturas aristocráticas se llevaban al extremo no podian resultar sino grotescas; como la del ministro que se negaba altivamente a aceptar el coche que compatriotas estaban acostumbrados a ofrecer al ministro español, pero cuyo presupuesto «me obliga a contentarme con tener un carruaje enganchado con dos caballos que puede decirse que es el.único de su género que circula por las calles de esta Capital». O la postura de aquel ministro que "con espíritu exageramente timorato" se negaba a aceptar la casa ofrecida por la colonia para sede de la legación porque «perdería con sus administrados el prestigio y libertad de que siempre debe gozar el Jefe de la Colonia" ${ }^{38}$.

La escasez de presupuesto conllevaba otras repercusiones, como la falta de material de oficina o la pobreza del mobiliario en las sedes diplomáticas; ambos conceptos entraban en partidas únicas en los presu-

\footnotetext{
${ }^{35}$ Estas tendencias conservadoras, además de los múltiples testimonios ya recogidos, pueden apreciarse claramente en la cólera incontenida ante "las doctrinas y teorias como las del amor libre y la desmilitarización absoluta" que apreciaba en las actividades de los maestros liberales el que fuera Secretario general del Ministerio de Estado; Bernardo Almeida al M. E.; Santiago de Chile, 14-I-1927; AMAE, Leg. H-2359. O en la admiración de Méndez de Vigo ante la presidencia del coronel lbáñez, guia de «todos los ciudadanos de acción y orden", de quien establece una semejanza con Primo de Rivera; Méndez de Vigo al M. E. Santiago de Chile, 12 y 18-IV-1927; AMAE, Leg. H-2359

${ }^{36}$ Algunos de estos informes tuvieron la dudosa fortuna de ser emitidos en puntos de inflexión política; como el del Embajador en Buenos Aires, felicitando la ley argentina que prohibia la participación de militares en la politica, remitido meses antes del golpe de Primo de Rivera. Marqués de Amposta al M. E.; Buenos Aires, 1-III-1923; AMAE, Leg. H-2317.

${ }^{37}$ Ramón Eubiezar al M. E.; Buenos Aires, 31-XI1-1898; AMAE H-1350. Las quejas sobre las dificultades económicas atravesadas por diplomáticos y cónsules son abundantes en todas las legaciones a lo largo de todo el periodo estudiado; una de las más explícitas fueron las siguientes: marqués de González al M. E.; México, 8-IX-1920; AMAE H-1659. S. Mariátegui al M. E; Habana, 2-V-1917; Archivo General de la Administración (AGA), A. E., Caja 65. Alejandro Padilla al M. E.; México, 24-IV-1927; AGA, A. E., Caja 65

${ }_{38}$ Marqués de González al M. E.; México, 8-VIII-1920; AMAE, Leg. H-1659.
} 
puestos y durante largos años se mantuvieron inamovibles. Pero la más trascendental consecuencia para el prestigio español en América se encontraba en la deficiente infraestructura inmobiliaria. Ocupando viejos caserones en precarias condiciones o pequeños pisos en modernos edificios, la comparación con los palacetes que ostentaban las potencias europeas era especialmente dolorosa para los representantes españoles. Lo que se agravaba ostensiblemente cuando no el prestigio sino el mero desempeño y la digna subsistencia eran los amenazados; lo que ocurría de modo generalizado en los consulados, sobre todo los que no coincidian con la capital del Estado ${ }^{39}$.

A partir de la reestructuración de presupuestos y servicios del Ministerio de Estado en 1926 se llevó a cabo un proyecto de reforma (tramitado ya en 1922) por el que se establecian seis categorias en las representaciones, atendiendo a las "zonas de carestía". América estaba encuadrada en el quinto grupo, entre los paises más baratos y por tanto con menos necesidad de aumento en los gastos representación y, sobre todo, en los gastos ordinarios de legaciones y consulados ${ }^{40}$.

Los presupuestos consignaban en el apartado “material» (gastos ordinarios) la inclusión de tan variadas necesidades como alquiler de casa, pago a empleados y compra del material de oficina; especialmente en los consulados, el montante total apenas alcanzaba para alguno de estos gastos, siendo por regla general el alquiler de casa lo único posible. Con el resto, la contratación de empleados era muy dificil y en consecuencia «el cónsul debe pagar todavia de su consignación papel, luz, calefacción, mobiliario y demás gastos menudos"; esta frase pertenece a un memorial que funcionarios del cuerpo consular remitieron al ministerio en demanda de mayores retribuciones, donde denuncian el estado en el que debian desempeñar su trabajo; el panorama que presenta supera con creces las peores críticas que emigrantes e hispanoamericanistas habian realizado ${ }^{41}$.

${ }^{39}$ «El resultado de esta penuria económica es que nuestros Consulados de Carrera van, valga la frase popular, a salto de mata, sin saber cómo ni dónde poderse instalar». Marqués de Desio al Ministro de Estado; México, 8-l-1926; AMAE H-1658.

${ }^{40}$ Los grupos establecidos (con un sospechoso seguimiento de las distancias) eran: $1 .^{\circ}$ Portugal; 2. ${ }^{\circ}$ Francia, Italia, Bélgica, Europa central, Marruecos, Gibraltar, Argelia y Túnez; 3. Gran Bretaña, Holanda, Suiza, Oriente europeo, y Asia Mediterránea; $4 .^{\circ}$ Paises escandinavos, Rusia y Egipto; 5. América Española, China y Japón; 6. Estados Unidos, Canadá, Australia, Persia, Brasil y Filipinas. "Memoria acerca del proyecto de presupuesto para el año económico 1922-1923 de la Sección II del Ministerio de Estado»; Madrid, 11-II-1922; AGA. A.E. Caja 67.

4. Memorándum sin titulo ni fecha [1921]; AGA, A.E., Caja 67. 
A estas denuncias de la insuficiente y deficiente representación española en América, de la mala calidad de los servicios y la escasa preparación de los funcionarios, los diplomáticos y cónsules se defendian con argumentaciones más o menos concretas. Ya se ha hecho referencia a las quejas por la falta de recursos, verdadera rémora para sus cometidos. Pero el fondo común de la defensa de los representantes fue el trasladar la responsabilidad de su falta de resultados a otras instancias.

En primer lugar a la propia colonia. Como más arriba se ha señalado, los contactos no siempre fueron positivos y los argumentos exculpadores tenian en su actitud unas posibilidades de variable aceptación. De la colonia se llegó a señalar su falta de patriotismo por ignorar el deber de registrarse en los consulados, donde se encontraban sólo entre el $10 \mathrm{y}$ 20 por 100 de los españoles residentes. En todo México existian sólo 6.583 españoles registrados en $1932^{42}$. Esto iba unido tanto al distanciamiento respecto a los representantes como a la división de la propia colonia, ya por enfrentamientos personales o por participación politica ${ }^{43}$. Más certero, Méndez de Vigo señalaba la diferenciación social de los integrantes de la colonia como causa principal de la falta de unión; esto tenia un paralelismo con las dificultades de los representantes oficiales de articular una política hacia la colonia que fuera bien aceptada por todos ${ }^{44}$.

Ser representantes de una monarquia en repúblicas orgullosas de serlo y con abierta animadversión por las dinastias, era para los diplomáticos un serio hándicap para la realización de su trabajo. Además se pretextaba el abierto o solapado republicanismo que mantenian muchas de las asociaciones, casinos y casas regionales españolas. Aunque con claras pruebas en tal sentido (algunas expuestas anteriormente), dicho argumento era poco veraz. En ningún momento, salvo en los últimos años de la dictadura primorriverista, hubo incidentes diplomáticos serios cuya causa pudiera, siquiera remotamente, achacarse al sistema monárquico español. Muy al contrario, durante las dos primeras décadas del siglo no sólo el conservadurismo, sino incluso el liberalismo americano fueron suavizando sus juicios hasta ser comunes las muestras de abierta admiración por Alfonso XIII. El golpe de estado del 23 dividió esta posición al hacer participe, para los liberales, de la dictadura militar al monarca.

Una nueva causa del mal resultado de la gestión diplomática era, según los mismos protagonistas, la escasa, cuando no nula, importancia que en el mismo Ministerio de Estado se daban a los informes enviados

\footnotetext{
${ }^{42}$ Intereses demográficos españoles; México, 1932; AMAE, Leg. R-721, exp. 6.

${ }^{43}$ José de Romero al M.E.; México, 24-XII-1906; AMAE, Leg. H-1658.

${ }^{44}$ Méndez de Vigo al M.E.; Santiago de Chile, 19-IX-1927; AMAE, Leg. H-2359.
} 
por los representantes. A todo aquel que siquiera superficialmente se haya acercado a la correspondencia diplomática, sorprenderá la falta de interés, sensibilidad e incluso mera curiosidad con que los encargados de la sección registraban las noticias, reflexiones o meras anécdotas de sus enviados. El comentario usual, "Enterado con interés», aparece en más de una comunicación de golpe de estado, revolución o asesinato politico.

Los cónsules, principales conductores y guias del intercambio comercial, además de repetir los obstáculos anteriores añadian algunos más para justificar la falta de incremento en los balances comerciales. En primer lugar la apatia de comerciantes e industriales peninsulares, creyentes de que América era un mercado tan «natural» que se debia rendir a sus productos sin ningún esfuerzo por su parte ${ }^{45}$. Esta «ineptitud y estupidez", como llegó a calificarlo un cónsul, para captar mercado hacia que no se enviaran a América agentes de comercio, oficiales o privados; o que cuando surgía un pedido especialmente importante no se controlaran los niveles de calidad esperados o incluso que se suministrara un artículo no solicitado. Por último, en numerosos informes transciende la idea de la poca importancia que el mercado americano tenía para el comercio español, debido al escaso poder adquisitivo de la mayoria de la población, la no complementación de ambas producciones y el largo recorrido necesario para llegar a los mercados más importantes; por lo que se aconsejaba dirigir los esfuerzos de la exportación al mercado europeo ${ }^{46}$. 944.

${ }^{45}$ Perada Blesa, E., "Consulado de España en Venezuela», BOME, 31-X-1898; págs. 941 -

${ }^{46}$ Serra, F., "Comercio entre Bélgica y las Repúblicas Hispanoamericanas"; BOME, $31-$ X-1901; pág. 841. Juicios más contundentes al respecto los del Cónsul en Valparaiso, LEYRA, G., "Memoria comercial correspondiente al año 1908», BOME, 28-11-1910; págs. 108-113. 